\title{
BRAIT, Beth (org). BAKHTIN: CONCEITOS-CHAVE. São Paulo: Contexto,2005.
}

\author{
Resenhado por: Fabiele Stockmans de Nardi $^{1}$
}

Retomar os textos de Bakhtin, ou um de seus conceitos, é, para mim, perguntar-me não só sobre a complexidade e riqueza de sua produção, mas sobre como pôde esse pensador, no silêncio que lhe impôs a situação política em que estava inserido, no espaço de gelo em que viveu, conceber uma língua tão acolhedora, tão cheia de vidas e vozes, essa língua viva que a tantos fascina e que convida a um incessante retorno aos seus textos.

São muitos os que têm perseguido os caminhos da escritura de Bakhtin, observado suas pegadas, tentando compreender as trilhas percorridas, os espaços por ele abertos. E foi justamente ao observar a atenção dedicada ao autor e seu Círculo nos últimos anos que Beth Brait organizou Bakthin: conceitos-chave, publicado pela editora Contexto. O livro, que reúne ensaios de pesquisadores, cujos trabalhos estão vinculados à produção desse filósofo da linguagem, é fruto de um intenso diálogo com/sobre as obras de Mikhail Mikhailóvitch Bakhtin, que somente começaram a ser conhecidas no ocidente, ainda de forma tímida, nos anos 70, em especial pela vertente de suas análises literárias.

Brait define, na introdução da obra, seu caráter pontual: "responder a insistentes e constantes questões que dizem respeito à maneira como conceitos, categorias e noções foram ganhando especificidade no conjunto dos trabalhos do Círculo" (p. 8). Seu propósito não é, portanto, esgotar a análise sobre as noções apresentadas no livro, mas investigar os conceitos que, considera, formam os pilares do pensamento bakthiniano.

Uma qualidade central dos ensaios reunidos na obra, e organizados em ordem alfabética, é colocar à mostra o diálogo intenso dos textos de Bakhtin com a produção filosófica de seu tempo, além de evidenciar a coerência temática e a clara linha conceitual, como comenta Sobral, que podemos encontrar nos trabalhos do Círculo.

Debruçar-se sobre os ensaios organizados por Brait é como olhar um mapa de viagem. Cada conceito é o ponto de partida de uma caminhada instigante pela rica produção de Bakhtin e seu Círculo, e caminhar pelos textos e deixar ver os caminhos é um compromisso que a obra realiza. Esse, entendo, é o seu ponto forte, mostrar a intensa produção desse pensador e a intrincada rede conceitual que constrói.

Cabe destacar, ainda, a preocupação, em cada um dos ensaios, de trazer exemplos de aplicação do conceito estudado. Por meio de análises, os autores fazem trabalhar as noções sobre as quais se debruçam, comprovando a atualidade do olhar proposto por Bakhtin sobre o discurso, que nos permite falar, a partir de seus textos, sobre processos/instâncias discursivas a respeito das quais, a exemplo do que diz Machado $^{2}$, ele nada disse, mas para as quais convergem suas formulações.

\footnotetext{
${ }^{1}$ Professora da Universidade de Caxias do Sul

${ }^{2}$ Graças a essa abertura conceitual é possível considerar as formulações discursivas do amplo campo da comunicação mediada, seja aquela processada pelos meios de comunicação de massa ou das modernas mídias digitais, sobre o qual, evidentemente, Bakhtin nada disso mas para o qual suas formulações convergem. (MACHADO, 2005, p. 152).
} 
É de Adail Sobral o primeiro ensaio do livro, aquele que convida para o passeio. Intitulado Ato/atividade e evento, o texto se propõe a discorrer sobre essas noções em termos filosóficos, seguindo a orientação de Bakhtin. Para isso, Sobral busca reconstituir as fontes que foram utilizadas pelo autor para formular o seu conceito, mostrando o que Bakthtin buscou (e também o que recusou) naqueles com quem se propôs a dialogar. O pesquisador nos oferece, desse modo, o complexo quadro das fontes de pesquisa que levaram o filósofo russo à sua concepção de ato e, também, um mapeamento dos textos em que essa noção aparece com destaque.

Ao comentar a leitura que Bakhtin faz do ato em Aristóteles, Platão e Husserl, Sobral afirma que na obra do pensador russo o "ato ultrapassa, em sua condição de processo concreto permanente, jamais acabado, toda e qualquer explicação que lhe retire a materialidade constitutiva e o reduza a algum conteúdo ou produto abstrato de natureza científica, filosófica ou estética" (p. 18). Aponta, assim, para uma característica que considera central na compreensão da noção de ato em Bakhtin: sua materialidade constitutiva.

Ao tratar da noção de ato e sua relação com o agente, o ensaísta propõe o neologismo "responsibilidade". Seu objetivo é "designar por meio de uma só palavra tanto o aspecto responsivo como o da assunção da responsabilidade do agente pelo seu ato, um responder responsável pelo que envolve necessariamente um compromisso ético do agente" (p. 20). Está olhando, nesse momento, o autor, para a ação do sujeito no mundo, para o agir do sujeito, nas palavras de Sobral, um agir situado e avaliativo de um sujeito marcado pela alteridade. E é justamente resposta e responsabilidade o que o autor destaca ao aplicar as noções de Bakhtin ao 11 de setembro, ato que é objeto de sua análise e que o leva a concluir que:

Ética, ato, atividade, ação, avaliação, responsabilidade e participatividade constituem, assim, em Bakthin, bases de uma proposta filosófico-cultural mais ampla, a de uma Lebensphilosophie que reconhece a total imersão do filósofo e de seu objeto na vida concreta, no agir situado, não-indiferente, ali onde não há álibi na existência. (p. 33).

Do ato para Autor e autoria. É assim que Carlos Alberto Faraco intitula seu ensaio, o segundo da obra sobre Bakhtin, que já inicia destacando uma importante distinção, entre o autor-pessoa (o escritor, o artista) e o autor-criador (função estéticoformal), esse sim objeto de estudo do filósofo russo. O autor-criador é a função estético-formal que engendra a obra. Trata-se de uma posição axiológica, "aquele constituinte do objeto estético", conforme expõe Faraco, "o pivô que sustenta a unidade do todo esteticamente consumado" (p. 37). É no olhar que lança sobre o herói e seu mundo que esse autor-criador se mostra, como uma função que dá forma ao conteúdo, uma voz segunda, uma voz social que dá unidade ao todo artístico.

[...] o autor-criador (a voz segunda) é, para Bakhtin, pura relação: não se trata de um ente físico (...), mas de uma função narrativa imanente que condensa, num todo estético, um determinado feixe de relações valorativas. (...) é um modo de ver o mundo, um princípio ativo de ver que guia a construção do objeto estético e direciona o olhar do leitor. (p. 42)

Organon, Porto Alegre, nº 47, julho-dezembro, 2009, p.225 - 230 
Incompletude, inconclusibilidade, alteridade, heteroglossia, polifonia. Essas são algumas noções que Faraco busca na obra de Bakhtin para mostrar essa nova forma de conceber a relação entre o autor e o herói, a autoria e a obra, entre a vida e a arte, a linguagem e o sujeito. Trata-se de um olhar para o estético e para o ético, como mostrará com minúcia Sobral, o olhar para um autor que não apenas fala do herói, mas que fala com ele, que o deixa falar; uma obra que não reflete o mundo, é uma forma de experimentá-lo.

Seguindo a ordem alfabética, Enunciado, enunciado concreto e enunciação, escrito por Beth Brait e Rosineide de Melo, marca a nossa terceira parada nessa trilha pelos conceitos do Círculo. Com um olhar atento, as autoras relembram que a leitura desses termos, como dos outros tantos trazidos à tona nesse trabalho, "só têm sentido na articulação com outros termos" (62), porque só na relação podemos encontrar a sua especificidade. E assim o é, também, entre os termos em análise, os quais estão de tal forma entrelaçados que a tentativa de separá-los resultaria no seu inevitável esvaziamento. É por isso que as autoras resolvem trabalhar os conceitos por meio de exemplos concretos, ou seja, ao analisar enunciados concretos, mostram que sua análise só faz sentido quando os remetemos a um projeto discursivo específico, e, portanto, a uma rede de relações.

E continuamos pelas palavras de Brait, mais especificamente por suas palavras sobre Estilo, conceito que, como diz a pesquisadora, "se apresenta como um dos conceitos centrais para se perceber, a contrapelo, o que significa, no conjunto das reflexões bakhtinianas, dialogismo, ou seja, esse elemento constitutivo da linguagem" (p. 80). Nesse ensaio, destaca-se o trabalho da autora em mostrar como estão ligadas as noções de estilo e dialogismo, o que a leva a afirmar que a questão do estilo, em Bakhtin, está em saber sob que ângulo dialógico se confrontam os componentes ou caracterizadores de um estilo.

Pertencem ao campo do discurso, portanto, as discussões sobre o estilo, sendo impossível sua determinação por critérios puramente lingüísticos. Mais do que isso, é fundamental observar que o estilo não se esgota na autenticidade individual, visto ser uma construção dialógica e, portanto, social. Como diz Brait, nas últimas linhas de seu ensaio, a concepção de estilo "implica sujeitos que instauram discursos a partir de seus enunciados concretos, de suas formas de enunciação, que fazem a ela e são a ela submetidos" (p. 98).

Ético e estético e Filosofias (e filosofia) em Bakhtin são os dois próximos ensaios do livro, ambos assinados por Adail Sobral, que mostra, novamente, o profundo conhecimento da produção do filósofo russo. No primeiro ensaio, merece destaque a análise feita pelo autor do que chama de dialogismo generalizado, o qual, segundo ele, incide fortemente sobre a noção de sujeito do Círculo, que implica a recusa das concepções transcendentais, psicologizantes ou da criatividade individual do sujeito. No segundo, o autor coloca em evidência os diálogos filosóficos travados por Bakhtin em sua obra, que divide entre maiores, menores e indiretos, e entre os quais destaca aquele travado com Kant.

Coube, na seqüência, a Irene Machado a tarefa de falar sobre Gêneros discursivos, noção que, segundo a autora, é fruto da necessidade, criada pela emergência da prosa, de "outros parâmetros de análise das formas interativas que se realizam pelo discurso" (p. 152). Aproximando a noção de gêneros discursivos daquela

Organon, Porto Alegre, n 47, julho-dezembro, 2009, p.225 - 230 
de dialogismo, Machado chama atenção para a especificidade do conceito dentro da teoria bakhtiniana, mostrando a necessidade de compreendê-lo como resultado do que designa de prosificação da cultura. "Mais do que reverter o quadro tipológico das criações estéticas, o dialogismo, ao valorizar o estudo dos gêneros, descobriu um excelente recurso para "radiografar" o hibridismo, a heteroglossia e a pluralidade de sistemas de signos da cultura". (p. 153).

É pelo viés da pluralidade, da heterogeneidade que se pode compreender os gêneros do discurso em Bakhtin, comenta Machado, para quem é preciso pensar o gênero como uma manifestação da cultura. O gênero, como expressão da cultura, é orientado pelo espaço-tempo de que é parte. Só se pode compreendê-lo, portanto, se o entendermos como forjado pela cultura, já que surge dentro de tradições com que, de alguma forma, se relaciona, o que faz com que o gênero seja, a cada edição (como as feiras, que Machado analisa), o mesmo e o outro.

$\mathrm{O}$ eu, o outro e a palavra retornam nos ensaios finais do livro, que se ocupam, respectivamente, dos conceitos de Ideologia, Palavra, Polifonia, Tema e significação.

No oitavo ensaio, Valdemir Miotello procura mostrar o tratamento dado à Ideologia nos trabalhos de Bakthin e de seu Círculo. Segundo Miotello, as reflexões sobre a ideologia nos trabalhos do Círculo partem de uma crítica à produção teórica marxista, que teria, então, dado um tratamento demasiado mecanicista ao conceito. Embora essa discussão inicial, entendemos, mereça maior refinamento ${ }^{3}$, cabe ressaltar o acertado destaque dado pelo autor à discussão, proposta em Marxismo e filosofia da linguagem, sobre a noção de signo ideológico. Conforme Miotello, pela noção de ideologia Bakhtin marca a impossibilidade de se conceber a neutralidade na linguagem, fazendo ver que toda mudança social se marca na língua.

Esse caráter essencialmente ideológico da linguagem é reforçado pelo trabalho feito por Paulo Rogério Bezerra no ensaio que dedica ao termo Palavra, por ele definido como "elemento concreto da feitura ideológica" (178). Aqui cabe uma pequena pausa para falar de uma afirmação que percorre todo o trabalho ora analisado, ou seja, a de que Bakhtin vai buscar, longe da pura abstração, olhar para os movimentos da linguagem pelo viés da concretude, de sua efetiva realização como discurso. E não é diferente com a palavra, que surge, portanto, como um produto ideológico resultante de um processo de interação na realidade viva. Conforme destaca Stella, a palavra faz-se signo ideológico porque acumula as entonações do diálogo vivo de que é matéria, ou, nos termos de Bakhtin, "cada palavra se apresenta como a arena em miniatura onde se entrecruzam e lutam os valores sociais de orientação contraditória" (p. 180).

Temos, portanto, uma palavra sem acabamento, essencialmente aberta às vozes sociais que a atravessam, prenhe de conteúdo histórico. Poderíamos dizer, assim, que a palavra em Bakhtin é polifônica, no sentido que, conforme nos mostra Paulo Bezerra, é preciso olhar para Polifonia na obra desse autor, ou seja, como signo de uma realidade sempre em formação, para a qual não há acabamento definitivo, realidade que é essencialmente inconclusa, dialógica.

\footnotetext{
${ }^{3}$ Talvez fosse esclarecedor um aprofundamento acerca das noções de ideologia oficial e ideologia do cotidiano, e da afirmação, feita por Miotello, de que "a ideologia encontra materialização aqui nas organizações sociais determinadas" (p. 174), com a discussão proposta por Louis Althusser sobre os aparelhos ideológicos de estado. Suspeito que essa leitura talvez pudesse levar a um outro olhar para a questão do assujeitamento, não raro compreendido como um aprisionamento do sujeito, determinação sem espaço de falhas.
} 
Bezerra nos faz retornar ao gênero romanesco para compreender a especificidade da noção de polifonia na obra de Bakhtin, o que só se pode fazer ao entendermos a "natureza ampla e multifacetada do universo romanesco" a que está vinculado o termo e todos que a ele se relacionam. Ao fazer isso nos remete inevitavelmente para os ensaios anteriores e, assim, para as noções de autor, de dialogismo, de gênero, entre outras. Ao analisar o romance Esaú e Jacob, de Machado de Assis, vai mostrar como:

[...] o autor, no romance polifônico, não define as personagens e suas consciências à revelia das próprias personagens, mas deixa que elas mesmas se definam no diálogo com outros sujeitos-consciências (...). Com o olhar deslocado do real móvel e vívido para a fiç̧ão, ele não reflete e recria um universo de objetos dóceis e surdos, passíveis de acabamento; reflete e recria a consciência dos outros e seus respectivos universos em permanente não-acabamento, não acabamento que é a própria essência dessas consciências [...] (p. 195).

Como mostrou Faraco, anteriormente, foi isso o que viu Bakhtin em Dostoiévski, essa forma distinta de se relacionar com o herói, esse diálogo intenso que faz do não acabamento um projeto estético.

No último ensaio do livro Willian Cereja fala sobre Significação e tema, fazendo um contraponto entre a virtualidade da significação, entendida como os sentidos potenciais que o signo assume (ou já assumiu) historicamente, e o aspecto concreto do tema, que além do sentido potencial do signo remete ao sentido que ele assume no momento histórico da enunciação. Embora devamos destacar o acerto com que o autor enfatiza o interesse da questão para os estudos da linguagem, creio que cabe reforçar o caráter relativo da simplicidade que menciona ao analisar os termos em questão, tarefa que obriga, necessariamente, a um compromisso com todo o universo conceitual desenvolvido por Bakhtin e seu Círculo.

Por fim, cabe ressaltar que a obra cumpre com seu propósito de, longe de representar uma palavra final sobre os termos em análise, propor um diálogo que nos leve a (re)encontrar os textos de Bakhtin e a trajetória conceitual que neles se constrói. Como um bom mapa de viagem, indica os caminhos e as paradas obrigatórias a fazer, destacando a necessidade de que olhemos para cada conceito de Bakhtin em seu necessário entrecruzamento com os demais, a fim de que não percamos de vista, como disse Brait, sua especificidade no conjunto dos trabalhos do Círculo. Bakhtin: conceitos-chave, mais que um convite à leitura da obra do filósofo russo, é uma prova de como ele se fez pesquisador, nos termos de Sobral, "na coerência teóricometodológica, na consistência ética, na consciência ética, no espelho da esfera em que ser pesquisador faz, e cria, sentido" (p. 118). 
